\title{
Field Protoype Experiment of Water Diversion for Typical River-net in Changshu City
}

\author{
Huang Xiangjin ${ }^{1, a}$, Xiang Long ${ }^{1, b^{*}}$, Liu Wangji ${ }^{1}$, Zhu Yongshu ${ }^{1}$ \\ ${ }^{1}$ College of Hydrology and Water Resources, Hohai University, Nanjing210098, China \\ a1970678561@qq.com , bxianglong@hhu.edu.cn ( ${ }^{*}$ corresponding author)
}

\begin{abstract}
Key words: Field Protoype Experiment; Water diversion; Hydrodynamic model; Water quality evaluation; Ecological restoration.

Abstract: Changshu city is located in Taihu Basin, where rivers are belonged to typical plain river-net. Recent years, water pollution in Changshu river-net is poor and serious threatened by potential industrialization and human activities. In order to understand the ecological restoration countermeasure, we conducted a Field Protoype Experiment(FPE) for water diversion in October 2014. Hydraulic and environmental data were collected by real time sampling in every 30min or $1 \mathrm{~h}$ at specifically cross-sections and duration time lasted for tidal cycle in Yangtze river. With the help of monitoring data, mathematical statistical and numerical method, we derived the flow distribution and water quality restoration conditions in whole river-net. The results suggested the water diversion has a great effect on the improvement of water environment quality in most of characteristic sections. Hydrodynamic model was used to calculate and simulated after calibrating by FPE data, then the river-reconnected and the improvement of regional water environment quality were tested. This study has discussed fully in the FPE method for water division and the conclusion is benefit for ecological restoration in this area.
\end{abstract}

\section{Introduction}

Changshu is located in the Yangtze river delta region, where the development of the industry, the expansion of population and urbanization is rapid. Due to the disorder of sewage drainage and the weak consciousness of environment protection the water environmental pollution becomes more and more serious. Especially the southwest area of Changshu, where is far from the Yangtze river, the water divsion distance is long and there are plenty of shallow rivers and dam block sections. Combined with the sewage discharged into rivers, control engineerings in the east of Wangyu river, the obtained water to the film area is less ${ }^{[1]}$.

It has a great progress in utilizing water diversion to improve regional water environment quality at home and abroad. Since the implementation of the project "Yin Jiang ji Tai" in 2002, water quality indicators can be stable in III basic classes in Wangyu river, upstream water quality of Tai hu lake and the Huang pu river has improved significantly. By guiding pure water into Xuanwu lake in Nanjing, improved the water quality and fundamentally solved the problem of eutrophication.Zhang jia gang ${ }^{[2]}$ and Tai cang city ${ }^{[3]}$ or Moscow river in Russia also carried water transfer experiments to improve water environment quality and the effects were great.

\section{Prototype water transferring experiment}

\section{Purpose of the experiment}

With the existing river conveyance capacity, working conditions and water environment in Changshu southwest area. Transferring water through Wangyu river from Yangtze, and observing water diversion of mainly channels ${ }^{[4]}$. 


\section{The experimental scheme}

In the district of the east of Wangyu river and the south of Zhangjiagang river, transferring water through Wangyu river from Yangtze, this water mainly open Yuntang lock, Beitang he lock,Liantang he lock and Hengtang lock to transfer water. Open the Baimao lock to drain away water 14 hours after ${ }^{[5]}$ Mainly monitoring programs are water level, flow rate and water quality (CODMn, NH3 - N, TP, TN). There are 18 water level and flow rate monitoring sections, 12 water quality monitoring sections, observating every $30 \mathrm{~min}$ or $1 \mathrm{~h}$.(Fig. 1) This experiment uses the different artificial time to read draft number for water level observation, the calculation of water level observation can take advantage of the arithmetic average and area surrounding method. For flow measurement, the main application is velocity area method, composed of measuring the velocity and the water area.Adopting sounding lead fish to measure depth of water in the experiment ${ }^{[6]}$.Water quality concentration measurement should first determine the sampling cross sections, setting the sampling sections where discharge a large number of residential waste into the river, upstream and downstream of industrial zone, main entrances and exit of rivers.Considering the depth of the water and flow rate, surface water samples can be getted by directly putting samplers below the surface of $0.3-0.5 \mathrm{~m}$, and jam-packing the sampling immediately to avoid contacting with air. Deep water samplings can use suction pump ${ }^{[7]}$.

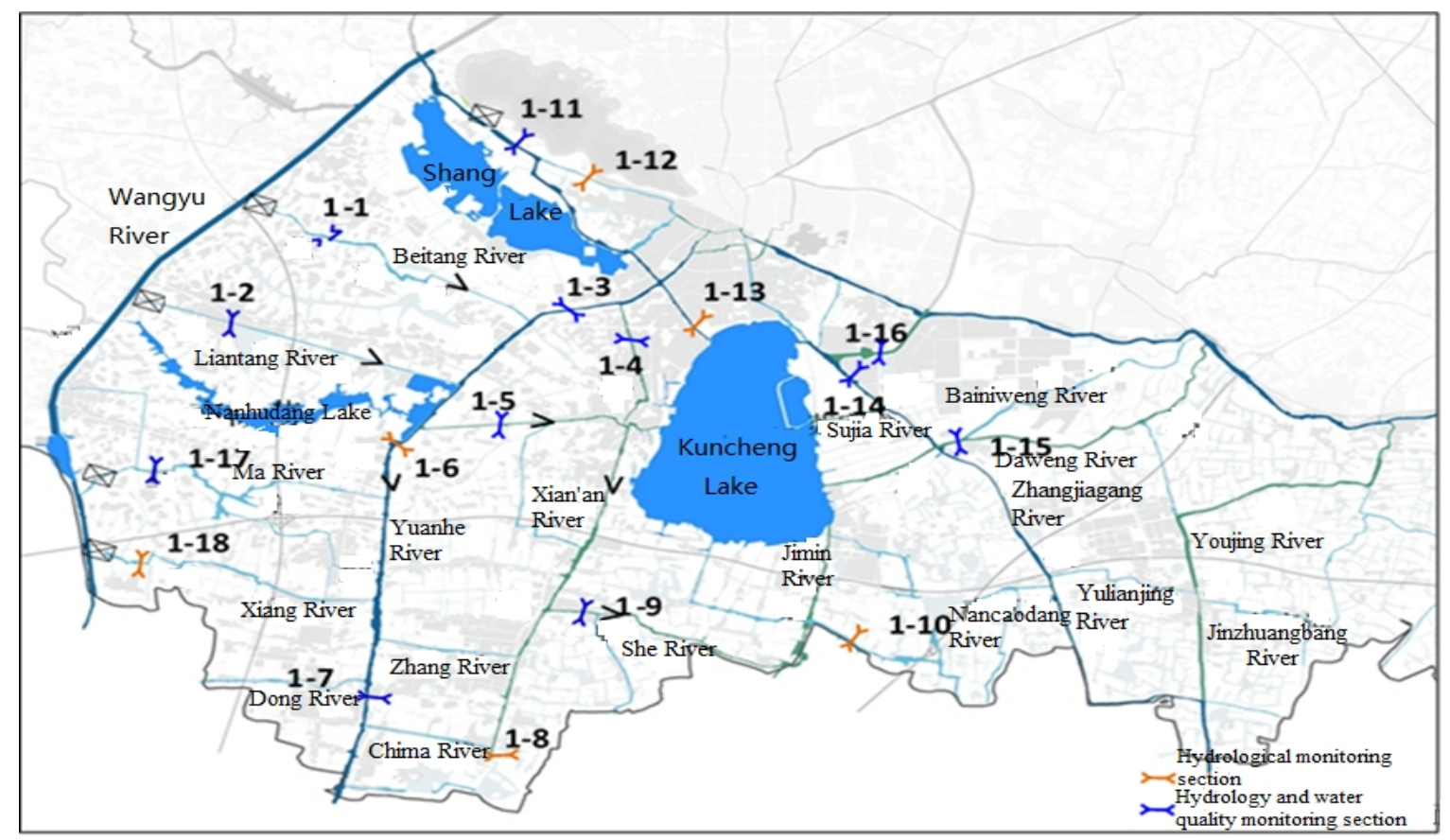

Fig1. The location of hydraulic and water quality monitoring sections

\section{Analysis of the water quantity and water quality monitoring data}

\section{Analysis of the water quantity data}

Intercept the biggest diverted section 1-11 in zhangjiagang river, bearing by 1-13, 1-14, 1-16 sections to do water data rationality analysis, more water diversion caused a large variance compared with other sections, at the same time the difference between the average, maximum and minimum is also large. The above data also reflected the shunt effect of the 1-16 section is not obvious. So the water diversion data can be used for split ratio calculation, and the simulation model.(Fig.2) 


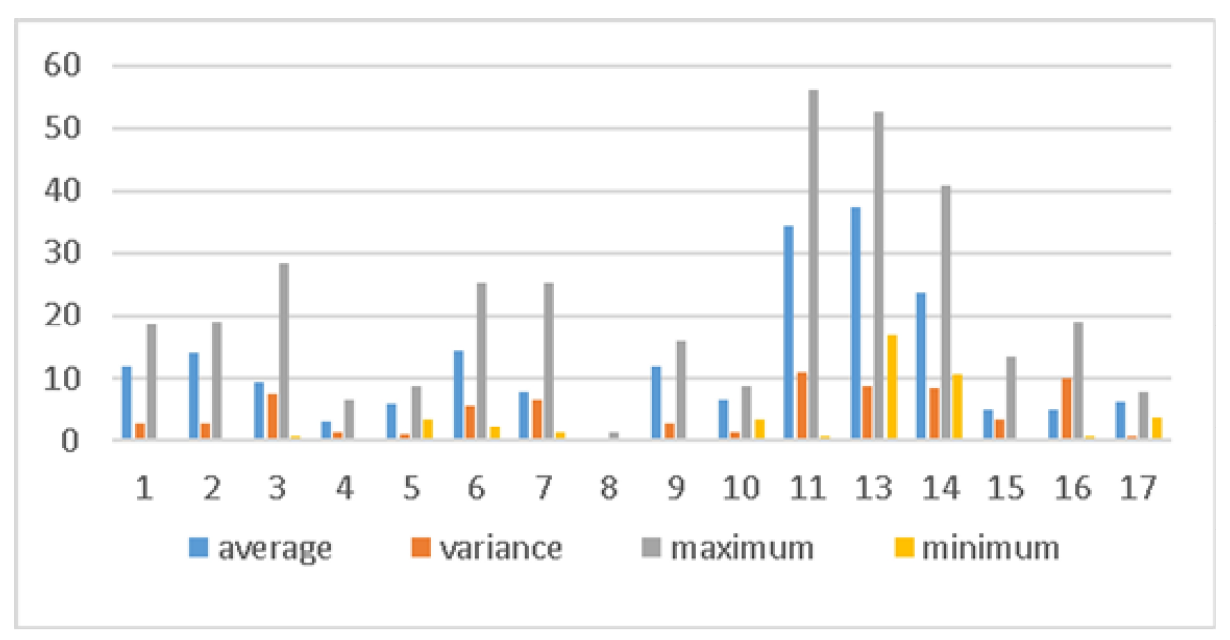

Fig2. Water quantity data analysis

In Kun cheng hu area, the improvement of pollutant concentration is high of 1-11 located in source monitoring area, explained that the water quality is good, which close to the source of the water. The average pollutant concentration of 1-14,1-15 sections after Kuncheng lake is larger than 1-11, on one hand is water pollution of Kuncheng lake, on the other hand, The water flow is small and the retention is serious. So the water quality data can be used in the calculation and model simulation.(Fig.3)

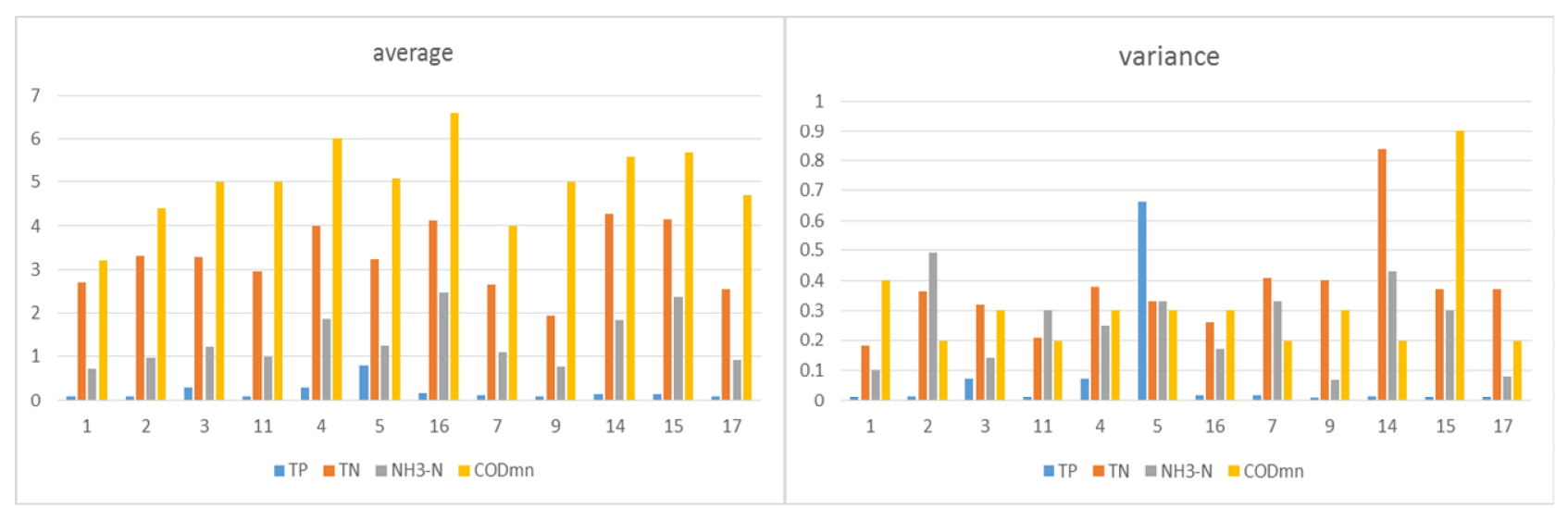

Fig3. Water quality data analysis

\section{Water quantity and quality analysis}

\section{Water quantity analysis}

For the entire experimental period and on the generalizability analysis of river network.Using split ratio to calculate ${ }^{[8]}$. The flow of Zhang jia gang River is the largest accounting for $56.7 \%$ and shunting by Yuan he Tang for $22.8 \%$. Which $22.4 \%$ of water flowed to Pei Jia Zhuang river by she jing , 71.7\% of water flowed to east branches of Zhang jia gang river through Kun Cheng lake. And the flow was significantly reduced about $20 \%$ after through Kuncheng lake, the flow of Ma Jing is smallest accunting for only $11.7 \%$. The amount of water flow during total diversion is about $282.7 \mathrm{~m}^{3}$. About $60 \%$ of the water discharged to branches of the Zhangjiagang river ,took away a large number of urban sewage to exchange water. The amount and maximum flow of the main sections during the water diversion experiment was expressed in Table 1. 
Table1. Water diversion quantity and maximum flow

\begin{tabular}{|c|c|c|}
\hline Section number & Water diversion quantity/[10ths. $\left.{ }^{3}\right]$ & Maximum flow $/\left[\mathrm{m}^{3} \cdot \mathrm{s}^{-1}\right]$ \\
\hline 1 & 64.6 & 18.6 \\
\hline 2 & 76.7 & 19.2 \\
\hline 3 & 51.0 & 28.4 \\
\hline 5 & 30.6 & 8.6 \\
\hline 6 & 78.1 & 25.2 \\
\hline 9 & 63.4 & 15.8 \\
\hline 11 & 160.2 & 56.1 \\
\hline 13 & 202.8 & 52.9 \\
\hline 14 & 54.1 & 40.9 \\
\hline 16 & 53.3 & 19.2 \\
\hline
\end{tabular}

Water quality analysis

Before water diversion, the sewage pressure of factories and residents continues to increase along the river, which impacted the water environment quality, accelerate the sedimentation, weakened the network storage capacity. Inland rivers affected by anthropogenic influences such as dam narrows, landfills. So the water flow is not fluent and pollution is serious within the area ${ }^{[9]}$.

Table 2. Water quality concentration changes in each section

\begin{tabular}{|c|c|c|c|c|}
\hline section & $\mathrm{TP}$ & $\mathrm{TN}$ & NH3-N & COD-Mn \\
\hline $1-1$ & $11.58 \%$ & $-5.15 \%$ & $-28.16 \%$ & $0.54 \%$ \\
\hline $1-2$ & $50.75 \%$ & $1.70 \%$ & $-11.14 \%$ & $4.40 \%$ \\
\hline $1-3$ & $-43.74 \%$ & $7.82 \%$ & $-16.24 \%$ & $-5.68 \%$ \\
\hline $1-11$ & $27.71 \%$ & $10.17 \%$ & $-35.61 \%$ & $6.04 \%$ \\
\hline $1-4$ & $112.49 \%$ & $-4.72 \%$ & $-22.73 \%$ & $-4.36 \%$ \\
\hline $1-5$ & $49.51 \%$ & $26.65 \%$ & $-3.91 \%$ & $-10.27 \%$ \\
\hline $1-16$ & $84.74 \%$ & $0.61 \%$ & $28.02 \%$ & $10.85 \%$ \\
\hline $1-7$ & $-8.45 \%$ & $42.11 \%$ & $62.33 \%$ & $1.73 \%$ \\
\hline $1-9$ & $25.18 \%$ & $-27.73 \%$ & $37.33 \%$ & $44.71 \%$ \\
\hline $1-14$ & $2.55 \%$ & $-12.03 \%$ & $-3.21 \%$ & $1.55 \%$ \\
\hline $1-15$ & $-8.87 \%$ & $13.01 \%$ & $22.85 \%$ & $16.57 \%$ \\
\hline $1-17$ & $19.22 \%$ & $34.00 \%$ & $12.22 \%$ & $1.84 \%$ \\
\hline
\end{tabular}

From improvement rate (Table.2)and single factor evaluations(Table.3), The concentration of pollutants in each section was improved in different degree.The concentration of TP, NH3-N and Mn in each section can basically meet the type III surface water requirements, which indicates that the water diversion is conducive to the acceleration of the regional water cycle and the improvement of the water quality. the concentrations of nitrogenous pollutant have an upward trend in water transfer section 1-1, 1-2,1-11.And the TP concentration of Chenghe 1-5 section exceeded the standard largely. So it is necessary to monitor the N, P pollutants concentration in the diversion sources and the concentration of pollutants from the source should be controlled ${ }^{[10]}$. 
Table 3. Single factor evaluation

\begin{tabular}{|c|c|c|c|c|}
\hline section & $\mathrm{Mn}$ & NH3-N & $\mathrm{TN}$ & $\mathrm{TP}$ \\
\hline \multirow{2}{*}{$1-1$} & 0.8 & 1.34 & 1.35 & 1.04 \\
\hline & II & II & $<\mathrm{V}$ & II \\
\hline \multirow{2}{*}{$1-2$} & 1.1 & 1 & 1.67 & 1.08 \\
\hline & II & III & $<\mathrm{V}$ & II \\
\hline \multirow{2}{*}{$1-3$} & 0.83 & 1.19 & 1.645 & 0.913 \\
\hline & III & III & $<\mathrm{V}$ & IV \\
\hline \multirow{2}{*}{$1-4$} & 1 & 0.9 & 1.995 & 0.805 \\
\hline & III & $\mathrm{V}$ & $<\mathrm{V}$ & III \\
\hline \multirow{2}{*}{$1-5$} & 0.85 & 1.21 & 1.645 & 1.938 \\
\hline & III & III & $<\mathrm{V}$ & $<\mathrm{V}$ \\
\hline \multirow{2}{*}{$1-7$} & 1 & 1.14 & 1.37 & 1.2 \\
\hline & II & III & $<\mathrm{V}$ & II \\
\hline \multirow{2}{*}{$1-9$} & 0.85 & 0.79 & 0.945 & 0.98 \\
\hline & III & III & $<\mathrm{V}$ & II \\
\hline \multirow{2}{*}{$1-11$} & 0.83 & 0.95 & 1.5 & 1.04 \\
\hline & III & III & $<\mathrm{V}$ & II \\
\hline \multirow{2}{*}{$1-14$} & 0.93 & 1.83 & 2.12 & 0.775 \\
\hline & III & III & $<\mathrm{V}$ & III \\
\hline \multirow{2}{*}{$1-15$} & 0.93 & 1.22 & 2.12 & 0.805 \\
\hline & III & IV & $<\mathrm{V}$ & III \\
\hline \multirow{2}{*}{$1-16$} & 1.08 & 1.245 & 2.065 & 0.88 \\
\hline & III & $\mathrm{V}$ & $<\mathrm{V}$ & III \\
\hline \multirow{2}{*}{$1-17$} & 1.175 & 0.95 & 1.29 & 0.93 \\
\hline & II & III & $<\mathrm{V}$ & II \\
\hline
\end{tabular}

\section{Water quantity and quality model}

\section{Model establishment and rate setting.}

According to the observed data and above present situation,to establish MIKE $11 \mathrm{HD}$ hydrodynamic model ${ }^{[11]}$, to obtain the difference of hydrodynamic characteristics (water level, flow velocity, flow, etc.) under different scheduling schemes.The governing equations of hydrodynamic module described in one-dimensional non constant water flow movement are Saint Venant equations, consisted of continuity equation of mass conservation and momentum equation of conservation of energy, respectively ${ }^{[13]}$ as:

$$
\begin{aligned}
& \frac{\partial A}{\partial t}+\frac{\partial Q}{\partial x}=q \\
& \frac{\partial Q}{\partial t}+\frac{\partial}{\partial x}\left(\frac{Q^{2}}{A}\right)+g A \frac{\partial h}{\partial x}+g \frac{Q|Q|}{C^{2} A R}=0 .
\end{aligned}
$$

Where $\mathrm{X}=$ distance; $\mathrm{t}=$ time; $\mathrm{A}=$ the area of flow section; $\mathrm{Q}=$ flow; $\mathrm{h}=$ water level; $\mathrm{q}=$ lateral flow; $\alpha=$ momentum coefficient, generally take for $1 ; \mathrm{C}=$ chezy coefficient; $\mathrm{R}=$ hydraulic radius; $\mathrm{g}=$ the acceleration of gravit.Using Abbott six point implicit scheme to discrete Saint Venant equations in MIKE11 HD model, given water level for $3.2 \mathrm{~m}$ as the initial condition, The roughness of river channel was setted for $0.03 \sim 0.05$. 


\section{The Simulation of design Schemes.}

Considering the limitations of the original scheme and the uncertainty of implementation of Zhangjiagang river course, one of the planned water circulation schemes is Ma Jing, Xiang Jing River as the diversion channel and Baimao Tang as the drainage channel.Through the broaden of village rivers to increase main drainage channels south of Kun cheng lake, and make the regional drainage pattern to be optimized, then flow to south of Yuan he Tang reduced to $3.5 \mathrm{~m}^{3} / \mathrm{s}$.and the distribution to the east increased, the flow lead to the boundary of sha jia bing increased $0.8 \mathrm{~m}^{3} / \mathrm{s}$ in the planned conditions. The diversion channels are ma jing,xiang jing and new zhang jia gang river in the other scheme, and the drainage channel is still Baimao Tang. The flow of water diversion in Mo cheng River reached to $2.0 \mathrm{~m}^{3} / \mathrm{s}$. The small area in north of Mo cheng river had a good water circulation, The river flow capacity of Pei Jia Zhuang after dredging increased and the flow lead to the boundary of sha jia bing increased to $1.8 \mathrm{~m}^{3} / \mathrm{s}$.(Table 4 )

Through the water system structure connectivity planning, stagnant water areas would be reduced, the flow distribution in the region can been optimized ${ }^{[12]}$.

Table 4. Flow distribution of key nodes in the study area

\begin{tabular}{|c|c|c|c|}
\hline \multicolumn{2}{|c|}{ section } & \multicolumn{2}{|c|}{$\begin{array}{l}\text { Average flow rate of water diversion } \\
\text { period }\left[\mathrm{m}^{3} / \mathrm{s}\right]\end{array}$} \\
\hline point & channel & Scheme 1 & Scheme 2 \\
\hline \multirow{4}{*}{1} & North of yuan he tang & 4.0 & 2.5 \\
\hline & South of yuan he tang & 0.5 & 6.0 \\
\hline & North of zhang jia gang river & 9.0 & 0.5 \\
\hline & South of zhang jia gang river & 4.5 & 3.0 \\
\hline \multirow{3}{*}{2} & North of yuan he tang & 0.5 & 6.0 \\
\hline & South of xin an tang & 2.0 & 5.5 \\
\hline & Xin an tang & 2.5 & 0.5 \\
\hline \multirow{3}{*}{3} & North of yuan he tang & 1.0 & 5.7 \\
\hline & South of yuan he tang & 7.5 & 5.0 \\
\hline & Mo cheng river & 1.0 & 2.0 \\
\hline \multirow{3}{*}{4} & North of xin an tang & 3.4 & 4.0 \\
\hline & South of xin an tang & 2.0 & 2.0 \\
\hline & She jing & 1.4 & 2.0 \\
\hline \multirow{3}{*}{5} & North of zhang jia gang river & 5.0 & 3.0 \\
\hline & South of zhang jia gang river & 3.4 & 1.8 \\
\hline & Dong huan river & 1.6 & 1.2 \\
\hline \multirow{4}{*}{6} & West of pei jia Zhuang river & 1.8 & 2.0 \\
\hline & East of pei jia Zhuang river & 1.5 & 1.8 \\
\hline & North of ji ming tang & 0.6 & 0.8 \\
\hline & South of ji ming tang & 0.3 & 0.5 \\
\hline
\end{tabular}

\section{Conclusions}

(1) Through analyzing the experimental data, we can conclude that using Yangtze river to diver water in southwest area to improve water environment is feasible. But prone to back flow and water congestion, the flow direction of the study area is complex.So it is very important to control water 
pollution and conduct project schedulings at the source. Diversion and sewage interception will be more effective based on dredging.

(2) Using Mike11 model to Discrete Saint Venant equations and determining the rationality of the model by the measured data of the water diversion experiment, based on the problems of river network, by broadening original village channels or Zhang jia gang river to ensure the flow distribution in the area to be optimized.

\section{Acknowledgements}

This study was supported by the National Natural Science Foundation of China (Grant No. 51309078, 51349015), Fundamental Research Funds for the Central Universities.

\section{References}

[1] He Wen xue, Zhou Bing, Chen Dongyun.The Scheme Design of Water Transfer and Water Distribution in Plain River Network Region to Improve Water Environment[J]. Water supply and drainage in China, 2012,36(17):63-67.

[2] Zhang Gang, Pang Yong, Cui Guangbo.Experimental Study and Model Establishment of Improving Water Environment in Taicang City[J]. Journal of safety and the environment, 2006,6(04):34-37.

[3] Wang Chao, Pang Yong, Cui Guangbo, Wei Zhen, Xu Xiangyang, Zhang Lei.Experimental Study and Data Model of Water Environment Regulation in Zhangjiagang[J]. Environmental science and technology, 2003,28(05):3-4.

[4] Ma Xiumei.Research on the Planning of Water System in Plain River Network Area[C]. Hohai University, (2006).

[5] Wang Chao, Wei Zhen, Zhang Lei, Zuo Jianying. Experimental Research on Water Environment Water Improvement in Plain River Network Region[J]. Journal of Hohai University,2003, 33(02):136-138.

[6] Ministry of Water Resources.Water Resources and Hydropower Engineering Design Flood Calculation Specification (SL44-2006)[M].China water conservancy and hydropower press, (2006).

[7] Mao Xinwei, Lu Mingfeng, Jia Xiaowang, Chen Yinda, Kao Yi. Water Diversion Structure Change and Its Impact along the Yangtze River west to the Wangyu River in Taihu Lake area [J]. Water Resources Development Research, 2010, 10 (9): 31-34.

[8] Chen Bo, Zhang Ze, Chen Ling, Yuan Zhihua, Sun Xiaohong. Eutrophication of Taihu Lake and Agricultural Non-point Source Pollution Control[J]. Agricultural Environmental Science, 2005,24 (S1):118-124.

[9] Li Hui, Su Baolin. Estimating Methods of Agricultural Non-point Source Pollution in Plain River Network Area [J]. Beijing Normal University: Natural Science Edition, 2009, 45 (Z1): 662-666.

[10] Zuo Junjie, Cai Yongli. Classification Method of Plain River Network Area Catchment Area: Taking Shanghai City as an Example[J]. Advances in Water Science, 2011,22(3):337-343.

[11] Han Longxi, Lu winter. Prospect of Research on Water Quality Model for River Plain[J]. Journal of Hohai University: Natural Science Edition, 2004 ,32(2):127-130.

[12] Huang Xuanwei. The Strategic Significance of Taihu Lake Water Transfer Project to Water Environment Improvement[J]. Water conservation,2002,36(03):36-39.

[13] Wang Li-li, Li Zhi-jia, Bao Hong-jun, 2010. Development and comparison of Grid-based distributed hydrological models for excess-infiltration runoffs. Journal of Hohai

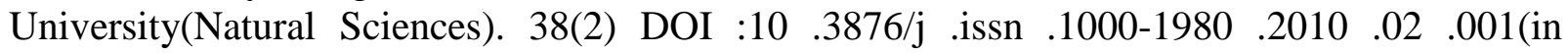
Chinese) 